\title{
Distance-driven species turnover in Bornean rainforests: homogeneity and heterogeneity in primary and post-logging rainforests
}

\author{
R. L. Kitching ${ }^{1 *}$, L. Ashton ${ }^{1}$, A. Nakamura ${ }^{1}$ and T. Whitaker ${ }^{2}$ \\ ${ }^{1}$ Environmental Futures Centre and Griffith School of Environment, Griffith University, \\ Nathan, Queensland 4111, Australia \\ ${ }^{2}$ Crowtrees, Low Bentham, Lancaster, LA2 7EE, United Kingdom \\ *Correspondence: R. L. Kitching, Environmental Futures Centre, Griffith University, \\ Nathan, Queensland 4111, Email: r.kitching@ griffith.edu.au
}




\section{ABSTRACT (A)}

Aim Selective logging is practiced extensively within tropical rainforests of south-east Asia, and its impact on local biodiversity is well documented. Little is known, however, about the impact of selective logging on patterns of spatial heterogeneity of species. We set out to test the hypothesis that selective logging will lead to a homogenization of the associated faunal assemblages, using moths (Lepidoptera) as our subject taxa.

Location Borneo, Danum Valley Conservation Area and surroundings, Sabah, Malaysia $\left(4^{\circ} 50^{\prime} \mathrm{N}-5^{\circ} 00^{\prime} \mathrm{N}\right.$ and $\left.117^{\circ} 35^{\prime} \mathrm{E}-117^{\circ} 45^{\prime} \mathrm{E}\right)$.

Methods Large-scale transects were established within primary and logged-over lowland mixed dipterocarp rainforests. Five study sites were located within each habitat with geometrically increasing inter-site distances. Macro-moths plus Pyraloidea were sampled by light trapping in 2007 and 2008. Vegetation state was also measured at each site.

Results A clear distance-decay relationship (decreasing assemblage similarity with increasing geographic distances) was observed in primary forest but was absent in the logged over forest. Large, comparable numbers of macro-moth species were found in both primary and logged-over forests. There were no significant differences in moth assemblage composition between primary and logged-over forests.

Main conclusions There are important structural differences between primary and logged-over forests reflected in the moth assemblages. A two-stage hypothesis combining both neutral and niche concepts is probably the most parsimonious explanation of these results. First, the composition of the moth assemblage is almost certainly determined locally by the variety of plant-hosts available to larvae, with the plants representing important niche dimensions for the moth species. Second the turnover (or lack of same) in the underlying plant assemblage probably reflects clumping and, in turn, dispersal capacity of the commoner plants in each forest type. Although the impact of selective logging may be subtle, this study suggests that selective logging results in the spatial homogenization of macro-moth assemblages.

\section{Keywords (B)}

Beta-diversity, species turnover, Borneo, Lepidoptera, niche, neutral theory, logging impacts 


\section{INTRODUCTION (A)}

The physical disruption caused by logging operations on tropical rainforests has produced evidence that the biodiversity and functioning of such logged-over forests may be seriously impacted (Sist et al., 2003a; Sist et al., 2003b; Meijaard et al., 2006; Paoli et al., 2008; Corlett, 2009). In terms of species richness, a range of studies of taxon-or habitat-specific assemblages have given only mixed levels of support to this contention (Holloway et al., 1992; Hill, 1999; Willott, 1999; Davis, 2000; Willott et al., 2000; Schulze et al., 2004; Deblauwe \& Dekoninck, 2007). Given the vast biological diversity associated with tropical rainforests such studies still concern a small proportion of taxa, locations and time periods. Further studies will shed light on the generality or otherwise of these earlier results.

In addition, anticipated post-logging impacts may be considerably more subtle than simple changes in species richness. As the physical structure of the forest is altered, so corresponding changes may be induced in community parameters such as food-web structure, guild partitioning, habitat diversity and, most pertinent to the present paper, patterns of spatial heterogeneity (Willott, 1999; Hill \& Hamer, 2004; Beck et al., 2006). All of these changes can occur within a zero-sum game of unchanging species richness and yet may have dramatic impacts upon ecosystem functioning and service provision. 
One hypothesis derived from these concerns, is that the disturbance regime associated with the logging process may impose a spatial homogeneity on species assemblages, in place of a distance-mediated dynamic turnover in species composition which might be expected to occur within an intact 'primary' rainforest (Nekola \& White, 1999; Chave \& Leigh, 2002; Morlon et al., 2008). Should this prove to be the case then questions arise as to what sorts of ecological processes may produce these patterns. The current neutrality/niche differentiation debates (see, e.g. Chesson, 2000; Hubbell, 2001; Leibold \& McPeek, 2006) are pertinent here, as are related issues of spatial scale as it relates to pattern in emergent properties of ecological communities. If neutrality is the dominant process determining place to place turnover in vegetation composition, then once spatially explicit processes are taken into account, a distance decay curve may be expected with steepness associated with the clumping regime of the underlying plants (Chave \& Leigh, 2002; Morlon et al., 2008). Of, course, such a relationship, may also arise if there is spatial habitat heterogeneity and the sort of compartment-based specialisation of communities noted for arthropods by, among others, Walter et al (1998) for mite assemblages, and C. Wardhaugh et al. (In preparation) for beetles in rainforests. Further, if place to place turnover is examined on too small a scale vis-à-vis the inherent or feasible vagility of the organisms being studied, then again no distance-decay relationship may be detected.

We have used the relatively well-known moth fauna of Sabah in northern Borneo to compare the patterns of species turnover across primary and logged-over lowland forest. 
We have used a mass sampling programme based on geometrically increasing inter-site distances from $100 \mathrm{~m}$ to $80000 \mathrm{~m}$ in each forest type to test the hypothesis outlined above.

We began with the a priori expectation that species turnover would be related to inter-site distance in undisturbed forest whereas place to place change in logged-over forest would show no such relationship.

\section{STUDY SITE AND METHODS (A)}

\section{Study area (B)}

The Danum Valley Field Centre is located on the Segama River in north-eastern Borneo in the Malaysian state of Sabah. The Field Centre is adjacent to the 43800ha Danum Valley Conservation Area $\left(4^{\circ} 50^{\prime} \mathrm{N}-5^{\circ} 00^{\prime} \mathrm{N}\right.$ and $\left.117^{\circ} 35^{\prime} \mathrm{E}-117^{\circ} 45^{\prime} \mathrm{E}\right)-$ a fully conserved region of undisturbed primary lowland dipterocarp forest. Both the Field Centre and the Conservation Area are embedded with the 1 million hectare Yayasan Sabah logging concession. This surrounding area has experienced various intensities of logging from the 1960's until very recently. Most of the logged-over areas have been allowed to regenerate naturally although some restoration by interplanting using dipterocarp saplings has occurred in a few areas.

In general the primary forest has a high density of dipterocarp trees frequently forming a closed canopy with relatively open understory. In contrast logged-over areas have relatively open canopies and a dearth of dipterocarp species (these being the primary 
targets of the logging industry). The few large trees left standing are those less favoured by the industry such as Koompasia excelsor (although following some logging regimes a small number of dipterocarp 'seed trees' also remain). The understory is frequently dense with mass thickets of gingers, climbing bamboos (Dinochloa spp.) and smothering vines as well as tree genera such as Macaranga, Octomeles and Neolamarkia characteristic of disturbed areas (Willott, 1999). Detailed descriptions of the flora and vegetation of the primary rainforests close to our study areas are provided by Newbery et al. (1992). Studies of the vegetation of the forests after logging are few but Woods (1989), Brearley (2004) and Bischoff et al. (2005) provide useful introductions and some survey data.

\section{Sampling design (B)}

We selected ten study sites, five in undisturbed primary forest and five in logged-over forest, at each of which we located three Pennsylvania-style light traps hung at about head height (Frost, 1957; Kitching et al., 2005). Traps were arranged about a focal point such that no trap was visible from any other. At each site three traps were run for several nights, until a moth sample of at least 1000 individuals of macro-moths with a wingspan greater than circa $8 \mathrm{~mm}$, had been accumulated.

Sampling was carried out during two field trips in the same period (December-March) in 2007 and 2008. Simple logistics prevented all 10 sites being sampled in the same year, and this is an acknowledged weakness in the study. Accordingly we sampled four 
primary forest and two logged-over forest sites in 2007, and two primary and four logged-over forest sites in 2008 . We resampled one primary and one secondary site in each year so that the year-to-year variation in diversity could be assessed (see below).

Within each forest type, sampling foci were located at geometrically increasing inter-site distances. From a base location and set of samples (Point 0), further samples were collected at $\mathrm{ca} 100 \mathrm{~m}, 1000 \mathrm{~m}, 10000 \mathrm{~m}$ and $80000 \mathrm{~m}$ distance (the most distant sites were located in the adjacent Imbak Canyon Conservation Area). This design gave us the ability to calculate assemblage similarities for inter-site distances within each forest 'treatment'. All sites occurred within a more or less continuous forest matrix.

All conventionally designated macro-moths (that is: members of the clade 'Macrolepidoptera' together with Hepialoidea, Zygaenoidea and Cossoidea plus Pyraloidea and Thyridoidea, (Grimaldi \& Engel, 2005) were removed from the samples and counted. This group of moths comprises a large portion of Lepidoptera in Borneo, representing more than 6800 recognised species (Holloway, 1986-2008, Whitaker unpublished data). All moths were identified to morpho-species and a substantial fraction have subsequently been named using the 18 volumes of Holloway (1986-2008), Robinson et al. (1994) and treatments in preparation for the Pyraloidea and Thyridoidea (T. Whitaker et al. unpublished.).

Lepidoptera are almost universally herbivorous in their larval stages (Scoble, 1992) and hence information on plant assemblages is useful in trying to explain moth diversity 
patterns. Accordingly plants were also surveyed within a circle of $20 \mathrm{~m}$ diameter, centred on each of the three light traps per site. The number of trees and their size classes were recorded, and abundance levels of other vegetation including seedlings and herbs were estimated using the semi-quantitative DAFOR scale where $5=$ dominant, $4=$ abundant, 3 $=$ frequent, $2=$ occasional, and $1=$ rare (Butterfield et al., 1991). All plants were identified to families and, where possible, to genus and/or species.

\section{Data analysis (B)}

We first compared moth species richness between primary and secondary forests. Although sampling intensity was standardized at approximately 1000 individuals, exact numbers varied from 1036 to 1269 . Species richness was therefore adjusted to a sample size of $\mathrm{N}=1000$ individuals, using individual-based species rarefaction curves generated for each site, based on the expected richness function (Mao Tau) using EstimateS ver. 8.2.0 (Colwell, 2009). Total species richness was estimated using the Abundance-base Coverage Estimator (ACE) of Chazdon et al. (1998), based on a standard sample of $\mathrm{N}=$ 1000 individuals per site.

As year-to-year variation was evident (see Results), statistical analyses treated sampling year as a random factor and habitat type as a fixed factor. For both univariate (species richness) and multivariate analyses (assemblage composition), we used a permutational multivariate analysis of variance (PERMANOVA) implemented in PRIMER 6 (ver. 6.1.13, Clarke \& Gorley, 2006) and PERMANOVA+ (ver. 1.0.3, Anderson et al., 2008) 
add-on software. The PERMANOVA routine tests for the effects of factors on one (such as species richness) or more (for example, assemblage composition) response variables, based on pseudo- $F$ statistics of the distance measures. Although PERMANOVA was developed primarily for multivariate analysis, univariate analysis is possible using Euclidean distances which yield Fisher's traditional univariate $F$ statistic (Anderson et al., 2008). Type III sums of squares were used to calculate $F$ statistics. Due to the limited number of possible permutations, Monte Carlo tests were conducted to obtain $P$ values using 4999 permutations of residuals under a reduced model.

Before assemblage-level analyses, moth species were subdivided into 'common' and 'rare' species. Common species were selected following Novotny et al. (2007) who calculated the probability of observing a species $(P)$ given $\mathrm{N}$ individuals from $\mathrm{n}$ sites, under an assumption of the extreme case where there is no beta-diversity within a given habitat, using the following equation: $P=1-(1-1 / \mathrm{n})^{\mathrm{N}}$. Threshold minimum abundance of common species $(\mathrm{N}=14)$ was calculated with $P=95 \%$ chance of detection from $\mathrm{n}=5$ sites within each habitat type. Abundances of 'common' moth species were then transformed to presence/absence binary data, and a Sørensen similarity index was used to measure assemblage similarities among pairs of sites. Only common species were incorporated into the calculation of these similarity measures, as inadequate sampling of rare species results in overestimation of beta-diversity (Novotny et al., 2007). In addition we used the relative abundance of both common and rare species to calculate Chao's abundance-based Sørensen similarity index (Chao-Sorensen index, Chao et al., 2005) in 
order to cross-validate the results obtained using the Sørensen index of common moth species (executed by EstimateS, ver 8.2.0, Colwell, 2009). Unlike other similarity indices that measure assemblage similarities using observed samples, the Chao-Sørensen index estimates the extent of shared species taking into account unseen shared species, based on the number of observed rare, shared species between two sites. The ChaoSørensen index is effective when samples are undersampled and contain a substantial fraction of rare species (Chao et al., 2005).

Variations in moth assemblage composition were also investigated visually using nonmetric multi-dimensional scaling (NMDS) ordination using PRIMER 6 software. Based on the triangular matrix of between-site similarity values, an NMDS ordination was generated using 25 random restarts with a First Kruskal fit scheme.

Of, courses pairwise comparisons among the five locations within each forest type are not wholly independent of each other (because the data from each location is involved in calculating similarities with several other sites). Accordingly we investigated distancedecay relationships between moth assemblage similarities and inter-site distances using Mantel tests calculated in R ver. 2.12.2 (R Development Core Team, 2011) and the vegan community ecology package ver. 2.0-1 (Oksanen et al., 2008). Mantel tests investigate whether two different matrices show similar patterns of inter-site variation using a correlation between two dissimilarity matrices (a Pearson correlation coefficient was used here), and test the significance of the statistic using Monte Carlo techniques. We tested 
the relationships between moth assemblage compositions (based on both the Sørensen and Chao-Sorensen indices) and geographic distances between sites (in metres, logtransformed and measured as Euclidean distances). In seeking a partial explanation for the patterns we found, we also examined the relationship between the patterns in moth assemblage composition and that observed for plant assemblages.

\section{RESULTS (A)}

Primary forests were characterised by greater proportion of large trees and larger number of large and medium size trees (Table 1). The proportion of dipterocarp trees was also greater within primary than secondary forest across all size classes. These differences, however, were not significant due to large between-site variations (Appendix 1).

In total, we sampled 13562 moths (6992 in primary forest and 6570 in post-logging forest), representing 1996 species (1393 in primary forest and 1468 in post-logging forest). Of these individuals, 7089 (1298 species) were caught in Year 1 and 6473 (1465 species) in Year 2. The similarity of abundances reflects the fact that we sampled each site until at least the requisite 1000 individuals were encountered (Table 2). They should not be taken as indications of relative abundance.

Two outcomes are of particular note based on the mean values of standardised species richness and ACE (both estimated at $\mathrm{N}=1000$ individuals) (Table 2). First, these values in primary and post-logging forest were comparable with no significant effect of habitat 
type (Table 3). Second, both standardized species richness and ACE in primary forest were higher in Year 2 than in Year 1 although there was no significant effect of year, nor interaction between habitat and year (Table 3).

In both forest types across both years of sampling there were very large numbers of 'rare' species. In primary forest, $94 \%$ (1308 species) of all species encountered fell into this category, in secondary forest, $95 \%$ (1394 species). This is not an unexpected outcome given the size of the Bornean moth fauna.

Figure 1. represents the results of our ordination analysis based on Sørensen similarity measures of common moth species. Although within-year points for primary and postlogging forest cluster separately from each other, the introduction of two samples from the additional year in each case obfuscates these differences especially in the primary forest samples. A PERMANOVA test suggests that the year to year differences are significant whereas the forest type differences and any interaction, are not (Table 3). Similar results were found when we used Chao-Sørensen similarity measures of both common and rare species.

The situation, however, is much clearer and more interesting when we examine the relationship between species turnover and inter-site distance within primary and postlogging forest types (Figure 2). We note, first, that the similarity values of moth assemblages in both forest types were remarkably high, ranging between $71 \%$ and $91 \%$ for Sørensen (that is: based on 'common' species only) and 65\% and 95\% for Chao- 
Sørensen similarity values (that is: based on all species). There was a negative relationship between assemblage similarity and the log of inter-site difference for primary forest. However, no such relationship existed for post-logging forests. Mantel tests confirmed the observed patterns, showing significant relationships between geographic distance and moth assemblages of primary, but not post-logging forest (Table 4). Moth assemblage composition was also strongly correlated to those of plant assemblages. However, the relationships were only significant for moth assemblage composition based on Chao-Sørensen index values.

\section{DISCUSSION (A)}

In trying to erect hypotheses to underpin our observations on both richness and turnover we first suggest that, almost without exception, local richness and assemblage structure for Lepidoptera will reflect locally available larval host plants. Although there are celebrated exceptions, (see, eg., Williams 1930) most adult Lepidoptera are not very vagile (Wilson \& Thomas, 2002) and probably spend their lives within a few tens or, at most, hundreds of meters of their birth sites. A large proportion are also layer-specialists with mixing between ground and canopy being the exception rather than the rule (eg. Brehm \& Linsenmair, Schulze \& Fielder, Ashton \& Kitching In preparation). In addition, most species are narrowly oligophagous often being restricted to a single genus or genus-group within a particular plant family (Dyer et al. 2007; Novotny, Basset \& Kitching 2003, Novotny et al. 2002, Basset, 1992). If we accept these two 
generalisations as axiomatic, then explanations of spatial pattern are best sought in ideas about the spatial patterning of the plant species which make up the local vegetation. Here a rich and informative literature is available.

Our comparisons of the species' totals in primary and post-logging secondary forests confirm earlier observations on Lepidoptera that each forest type presents similar levels of richness (e.g. Hamer et al. 2003, Willott 1999). Likewise we detected no significant overall differences in assemblage composition between these two habitat types, despite strong evidence of year-to-year variations. The similar levels of species richness encountered in primary and post-logging forest may be explained when we take into account the range food-plant driven opportunities provided for establishment of specific moth populations. The species composition in the understorey of primary forest is likely driven by the availability of ombrophilous shrubs, seedlings of canopy trees, woody and non-woody vines, plus vascular and non-vascular epiphytes, plus a few species will originate in the leaf litter and fallen timber. Herbaceous plants are relatively rare under closed canopies. In contrast, in post-logging forests, the canopy is almost always substantially disturbed and simplified with concomitant loss of woody vines and epiphytes (Johns 1988). This may be compensated for, however, by vastly increased availability of non-woody vines, herbs, and ferns. Grasses, gingers, scrambling palms and other vigorous monocotyledons are a much more apparent part of the flora in these post-logging forests. It seems likely that this compensates for the inevitable loss of the 
canopy components of the fauna to produce the closely similar richness measures across the two forest types.

Turning to spatially driven turnover patterns, we found contrasting differences between the two habitat types: the presence of distance-mediated spatial heterogeneity was evident within primary forest but not within the post-logging forests. Effects of year-to-year variation may have confounded our results as the majority of primary and post-logging forests were sampled in different years. Nevertheless, the trend in results was consistent whether or not the analyses was conducted within the same year or across different years, which reinforced our notion that a distance-decay relationship exists in primary but not post-logging secondary forests in Bornean rainforests.

Our finding appears to be inconsistent with those of Novotny et al. (2007) who found low beta diversity in New Guinean tropical rainforests. It is interesting to note that both Novotny and his co-workers and we found relatively high species overlaps among sites (i.e. low beta diversity). Our study, however, detected subtle, yet highly significant differences in beta diversity with increased geographic distances between sites. This apparent difference between the two studies may be the result of the different spatial scales used. Our study examined inter-site distances of 0.4 to $80 \mathrm{~km}$, whereas Novotny et al. (2007) examined the range, 100 to $600 \mathrm{~km}$. Beck and Khen (2007) found distancedecay relationships in geometrid moth assemblages in Bornean rainforests, but the relationships they observed were evident at smaller spatial scales with inter-site distances 
of less than $20 \mathrm{~km}$ and were only detectable after controlling for other parameters such as elevation and human-mediated disturbances.

The distance-decay relationship that we have identified in primary forest has been widely supported and debated in the literature (for key references see Introduction). Much recent attention has been focussed on neutral explanations of vegetation in which local diversity is viewed as being drawn from a species pool with little if any determinism concerning local success of particular species (Hubbell, 2001, Condit et al. 2002). Recent authors have incorporated explicit spatial dynamics into the fundamental theory of Hubbell (Chave \& Leigh 2002, Morlon et al. 2008) showing how the 'traditional' distance-decay curve emerges with only minimal additional parameters related to local, perhaps transient, 'clumping' of species. The most likely driver of such clumping is dispersal limitation. In their model, based on a Poisson cluster process acting upon presence or absence of species, Morlon et al. (2008) show in addition that this pattern is largely generated by the commoner species in any location with rare species playing only a minor role. This insensitivity to rare species even when abundance-based similarity measures are used is also confirmed by Nekola and White (1999). Morlon et al. (2008) also show that the shape of the relationship is insensitive to overall species richness. It is feasible that place to place turnover in plant composition - and, in consequence, of moth assemblages - reflects topographic and pedological heterogeneity with distance producing new opportunities ('niches') for different species. This is not the most parsimonious explanation and, in any case, would not account for the absence of a 
distance decay relationship in the logged over forest, where at least most of the topography and gross soil characteristics will persist, albeit in locally rearranged form.

We suggest, therefore, that the clear turnover we observe in moth assemblages in primary forest is adequately explained by neutral explanations of vegetation change. These changes then provide different available niche dimensions (through the availability of food plants) for moths thereby producing the patterns of moth turnover we observe. This combination of neutral and niche drivers of pattern may well have wider applicability for accounting for beta diversity in animal assemblages.

The same logic can be applied in seeking an explanation for the flat (or absent) distancedecay relationship in logged-over forest. Here our argument demands a more or less uniform set of available food plants. Under the spatially explicit neutral model the most parsimonious way of positing this is by hypothesising that the logged-over forests are dominated by plant species which have exceptionally well developed dispersal mechanisms. This is not to say that the same aggregative mechanisms would not apply in these forests, just that they would operate over a much larger spatial scale. The dominance of regenerating rainforests by plants having a high vagility has been observed by several authors (Gorchov et al. 1993, Dalling et al. 2002, Willson \& Crome 1989).

These results have considerable implications for conservation. They suggest that the effectiveness of ecosystem management for conservation cannot be monitored simply by assessing species richness. Species turnover is a vital marker if vibrant healthy forests 
are to be maintained. Conceivably this requires more landscape management to maintain patches of intact canopies scattered through post-logging forests. Depending on the target taxa this may require particular attention to the spatial scale of these patches.

\section{ACKNOWLEDGEMENTS (A)}

This work was carried out at the Danum Valley Field Studies Centre in Sabah and we gratefully acknowledge Yayasan Sabah, the Danum Valley Management Committee (particularly Dr Waidi Sinun), the State Secretary, Sabah Chief Minister's Department, and the Economic Planning Unit of the Prime Ministers Department for permission to conduct this work. We also thank Dr Glen Reynolds for day to day advice and support during the field work. Messrs En. Jamaludin Jamil, En. Alex Karolus, En. Anthony Karolus, En. Nasir Majid and En. Mohd. Nazran Yaakub provided able research assistance during the field work. The study was Project Number RS263 of the Danum Valley Rainforest Research and Training Programme and the research was supported by the Royal Society (SEARRP) and by a National Geographic Society, Washington (grant number 8024-06). We gratefully acknowledge Professor Stuart Pimm, Dr Chey Vun Khen, Professor Jane Hill and Dr Chris Hamer for their advice during the preparation of the research proposal. These persons together with Professors Nigel Stork and Hamish McCallum kindly commented upon an earlier version of the manuscript. 


\section{REFERENCES (A)}

Anderson, M.J., Gorley, R.N. \& Clarke, K.R. (2008) PERMANOVA+ for PRIMER: Guide to Software and Statistical Methods. PRIMER-E, Plymouth.

Beck, J. \& Khen, C.V. (2007) Beta-diversity of geometrid moths from northern Borneo: effects of habitat, time and space. Journal of Animal Ecology, 76, 230-237.

Beck, J., Mandel, F. \& Peer, M. (2006) Geometrid moths (Lepidoptera, Geometridae) in Borneo: how homogenous are assemblages from a 'uniform' lowland primary forest? Journal of the Zoological Society Wallacea, 2, 44-53.

Bischoff, W., Newbery, D.M., Lingenfelder, M., Schnaeckel, R., Petol, G.H., Madani, L. \& Ridsdale, C.E. (2005) Secondary succession and dipterocarp recruitment in Bornean rain forest after logging. Forest Ecology and Management, 218, 174-192.

Brearley, F.Q., Prajadinata, S., Kidd, P.S., Proctor, J. \& Suriantata (2004) Structure and floristics of an old secondary rain forest in Central Kalimantan, Indonesia, and a comparison with adjacent primary forest. Forest Ecology and Management, 195, 385-397.

Butterfield, J.E.L., Coulson, J.C. \& Whittaker, J.B. (1991) The response of terrestrial invertebrates to climate change. A report comissioned by Natural Environment Research Council, Swindon. In, p. 32

Chao, A., Chazdon, R.L., Colwell, R.K. \& Shen, T.J. (2005) A new statistical approach for assessing similarity of species composition with incidence and abundance data. Ecology Letters, 8, 148-159.

Chave, J. \& Leigh, E.G. (2002) A spatially explicit neutral model of beta-diversity in tropical forests. Theoretical Population Biology, 62, 153-168.

Chazdon, R.L., Colwell, R.K., Denslow, J.S. \& Guariguata, M.R. (1998) Statistical methods for estimating species richness of woody regeneration in primary and secondary rain forests of NE Costa Rica. Forest biodiversity research, monitoring and modeling: Conceptual background and Old World case studies (ed. by F. Dallmeier and J.A. Comiskey), pp. 285-309. Parthenon Publishing, Paris. 
Chesson, P. (2000) Mechanisms of maintenance of species diversity. Annual Review of Ecology and Systematics, 31, 343-366.

Clarke, K.R. \& Gorley, R.N. (2006) PRIMER v6: User Manual/Tutorial. Primer-E Ltd., Plymouth.

Colwell, R.K. (2009) EstimateS: Statistical estimation of species richness and shared species from samples. Version 8.2. User's guide and application published at: http://purl.oclc.org/estimates.

Condit, R., Pitman, N., Leigh, E.G., Chave, J., Terborgh, J., Foster, R.B., Núñez, P., Aguilar, S., Valencia, R., Villa, G., Muller-Landau, H.C., Losos, E. \& Hubbell, S.P. (2002) Beta-diversity in tropical forest trees. Science, 295, 666-669.

Corlett, R.T., Oxford University Press, . (2009) The Ecology of Tropical East Asia.

Davis, A.J. (2000) Does reduced-impact logging help preserve biodiversity in tropical rainforests? A case study from Borneo using dung beetles (Coleoptera: Scarabaeoidea) as indicators. Environmental Entomology, 29, 467-475.

Deblauwe, I. \& Dekoninck, W. (2007) Diversity and distribution of ground-dwelling ants in a lowland rainforest in southeast Cameroon. Insectes Sociaux, 54, 334-342.

Dornelas, M., Connolly, S.R. \& Hughes, T.P. (2006) Coral reef diversity refutes the neutral theory of biodiversity. Nature, 440, 80-82.

Frost, S.W. (1957) The Pennsylvania insect light trap. Journal of Economic Entomology, 50, 287-292.

Grimaldi, D. \& Engel, M.S. (2005) Evolution of the Insects. Cambridge University Press, Cambridge.

Hamer, K.C., Hill, J.K., Benedick, S., Mustaffa, N., Sherratt, T.N., Maryati, M. \& K, C.V. (2003) Ecology of butterflies in natural and selectively logged forests of northern Borneo: the importance of habitat heterogeneity. Journal of Applied Ecology, 40, 150-162.

Hanski, I. (1998) Metapopulation dynamics. Nature, 396, 41-49. 
Hill, J.K. (1999) Butterfly spatial distribution and habitat requirements in a tropical forest: impacts of selective logging. Journal of Applied Ecology, 36, 564-572.

Hill, J.K. \& Hamer, K.C. (2004) Determining impacts of habitat modification on diversity of tropical forest fauna: the importance of spatial scale. Journal of Applied Ecology, 41, 744-754.

Holloway, J.D. (1986-2008) Moths of Borneo, Vol. 1, 3-18. Southdene Sdn. Bhd., Kuala Lumpur.

Holloway, J.D., Kirk-Spriggs, A.H. \& Khen, C.V. (1992) The response of some rain forest insect groups to logging and conversion to plantation. Philosophical Transactions of the Royal Society of London. Series B: Biological Sciences, 335, 425-436.

Hubbell, S.P. (2001) The Unified Neutral Theory of Biodiversity and Biogeography. Princeton University Press, Princeton.

Johns, A.D. (1988) Effects of" selective" timber extraction on rain forest structure and composition and some consequences for frugivores and folivores. Biotropica, 20, 3137.

Kitching, R.L., Boulter, S.L., Vickerman, G., Laidlaw, M., Hurley, K.L. \& Grimbacher, P.S. (2005) The Comparative Assessment of Arthropod and Tree Biodiversity in OldWorld Rainforests, 2nd edn. Rainforest CRC \& Earthwatch Institute, James Cook University, Cairns.

Leibold, M.A. \& McPeek, M.A. (2006) Coexistence of the niche and neutral perspectives in community ecology. Ecology, 87, 1399-1410.

Meijaard, E., Sheil, D., Nasi, R. \& Stanley, S.A. (2006) Wildlife conservation in Bornean timber concessions. Ecology \& Society 11, 47 [online] URL: http://www.ecologyandsociety.org/vol11/iss1/art47/

Morlon, H., Chuyong, G., Condit, R., Hubbell, S., Kenfack, D., Thomas, D., Valencia, R. \& Green, J.L. (2008) A general framework for the distance-decay of similarity in ecological communities. Ecology Letters, 11, 904-917. 
Nekola, J.C. \& White, P.S. (1999) The distance decay of similarity in biogeography and ecology. Journal of Biogeography, 26, 867-878.

Newbery, D.M., Campbell, E.J.F., Lee, Y.F., Ridsdale, C.E. \& Still, M.J. (1992) Primary lowland dipterocarp forest at Danum Valley, Sabah, Malaysia: structure, relative abundance and family composition. Philosophical Transactions of the Royal Society of London. Series B: Biological Sciences, 335, 341-356.

Novotny, V., Basset, Y. \& Kitching, R.L. (2003) Herbivore assemblages and their food resources. Arthropods of Tropical Forests. Spatio-temporal Dynamics and Resource Use in the Canopy (ed. by Y. Basset, V. Novotny, S.E. Miller and R.L. Kitching), pp. 40-53. Cambridge University Press, Cambridge

Novotny, V., Miller, S.E., Hulcr, J., Drew, R.A.I., Basset, Y., Janda, M., Setliff, G.P., Darrow, K., Stewart, A.J.A., Auga, J., Isua, B., Molem, K., Manumbor, M., Tamtiai, E., Mogia, M. \& Weiblen, G.D. (2007) Low beta diversity of herbivorous insects in tropical forests. Nature, 448, 692-695.

Oksanen, J., Kindt, R., Legendre, P., O'Hara, B., Simpson, G.L., Henry, M. \& Stevens, H. (2008) Vegan: community ecology package R Package version 1.11-4.

Paoli, G.D., Curran, L.M. \& Slik, J.W.F. (2008) Soil nutrients affect spatial patterns of above-ground biomass and emergent tree density in southwestern Borneo. Oecologia, 155, 287-299.

R Development Core Team (2011) R: A Language and Environment for Statistical Computing. R Foundation for Statistical Computing, Vienna.

Robinson, G.S., Tuck, K.R. \& Shaffer, M. (1994) A Field Guide to the Smaller Moths of South-East Asia. Malaysian Nature Society \& The Natural History Museum, Kuala Lumpur.

Schulze, C.H., Waltert, M., Kessler, P.J.A., Pitopang, R., Shahabuddin, Veddeler, D., Mühlenberg, M., Gradstein, S.R., Leuschner, C., Steffan-Dewenter, I. \& Tscharntke, T. (2004) Biodiversity indicator groups of tropical land-use systems: comparing plants, birds, and insects. Ecological Applications, 14, 1321-1333.

Scoble, M.J. (1992) The Lepidoptera: form, function, and diversity. Oxford University Press, Oxford. 
Sist, P., Picard, N. \& Gourlet-Felury, S. (2003a) Sustainable cutting cycle and yields in a lowland mixed dipterocarp forest of Borneo. Annals of Forest Science, 60, 803-814.

Sist, P., Sheil, D., Kartawinata, K. \& Priyadi, H. (2003b) Reduced impact logging in Indonesian Borneo: some results confirming the need for new silvicultural prescriptions. Forest Ecology and Managament, 179, 415-427.

Walter, D.E., Seeman, O., Rodgers, D. \& Kitching, R.L. (1998) Mites in the mist: How unique is a rainforest canopy-knockdown fauna? Australian Journal of Ecology, 23, 501-508.

Willott, S.J. (1999) The effects of selective logging on the distribution of moths in a Bornean rainforest. Philosophical Transactions of the Royal Society of London. Series B: Biological Sciences, 354, 1783-1790.

Willott, S.J., Lim, D.C., Compton, S.G. \& Sutton, S.L. (2000) Effects of selective logging on the butterflies of a Bornean rainforest. Conservation Biology, 14, 10551065 .

Woods, P. (1989) Effects of logging, drought, and fire on structure and composition of tropical forests in Sabah, Malaysia. Biotropica, 21, 290-298. 


\section{Tables}

Table 1. Mean and standard error (in parentheses) of plant species richness across, proportion of large trees to all other size classes (viz. large, medium and small trees) and proportion of Dipterocarp trees . Values are subdivided for the different tree size classes and other vegetation (seedlings and herbs).

\begin{tabular}{lrll}
\hline & & Primary forest & Post-logging forest \\
\hline Proportion of large trees & & $0.420(0.097)$ & $0.267(0.090)$ \\
Species richness & & \\
& Large trees & $4.2(0.9)$ & $2.8(0.9)$ \\
& Medium trees & $8.4(1.9)$ & $7.8(1.0)$ \\
Small trees & $1.8(0.7)$ & $3.2(1.0)$ \\
\multicolumn{1}{c}{ Seedlings and other vegetation } & $10.2(1.0)$ & $8.8(1.1)$ \\
& All & $19.0(1.6)$ & $18.2(2.8)$ \\
Proportion of Dipterocarp trees & & & \\
& Large trees & $0.776(0.091)$ & $0.562(0.167)$ \\
& Medium trees & $0.352(0.088)$ & $0.192(0.041)$ \\
Small trees & $0.400(0.187)$ & $0.107(0.066)$ \\
\hline
\end{tabular}


Table 2. Mean and standard error (in parentheses) of moth abundance, species richness, estimated species richness (ACE) and the number of common and rare species per site. Values are also subdivided for the data collected in year 1 and 2.

\begin{tabular}{lll}
\hline & Primary forest & Post-logging forest \\
\hline Number of individuals & $1165(40.9)$ & $1095(22.8)$ \\
Year 1 & $1211(44.3)$ & $1081(24.1)$ \\
Year 2 & $1075(33.0)$ & $1124(55.5)$ \\
Species richness at 1000 individuals & $468(17.5)$ & $501(8.3)$ \\
Year 1 & $453(23.1)$ & $500(11.6)$ \\
Year 2 & $497(7.6)$ & $503(15.0)$ \\
ACE at 1000 individuals & $1236(80.5)$ & $1213(39.2)$ \\
Year 1 & $1146(90.3)$ & $1182(44.9)$ \\
Year 2 & $1415(3.5)$ & $1273(73.8)$ \\
Number of common species & $94(2.2)$ & \\
Year 1 & $96(3.0)$ & $93(0.8)$ \\
Year 2 & $91(1.5)$ & $93(1.3)$ \\
Number of rare species & $362(17.1)$ & $94(0.5)$ \\
Year 1 & $343(18.5)$ & $397(15.3)$ \\
Year 2 & $402(7.5)$ & $404(19.4)$ \\
\hline
\end{tabular}


Table 3. Summary results of PERMANOVA, showing pseudo- $F$ and $P$ values $(P$ values obtained from Monte-Carlo permutations) of habitat, year and their interaction effects on species richness (univariate) and assemblage (multivariate) data. Degrees of freedom for habitat, year, interaction and error were $1,1,1$ and 8 respectively.

\begin{tabular}{|c|c|c|c|c|c|c|}
\hline & \multicolumn{2}{|c|}{ Habitat } & \multicolumn{2}{|c|}{ Year } & \multicolumn{2}{|c|}{ Interaction } \\
\hline & Pseudo- $F$ & $P$ & Pseudo- $F$ & $P$ & Pseudo- $F$ & $P$ \\
\hline \multicolumn{7}{|l|}{ Univariate data } \\
\hline Standardised species richness & 1.26 & 0.453 & 1.09 & 0.324 & 1.40 & 0.282 \\
\hline $\mathrm{ACE}$ & 0.09 & 0.813 & 1.27 & 0.300 & 5.19 & 0.053 \\
\hline \multicolumn{7}{|l|}{ Multivariate assemblage data } \\
\hline $\begin{array}{l}\text { Sørensen similarity measures on } \\
\text { 'common' species only }\end{array}$ & 3.34 & 0.083 & 4.98 & 0.005 & 0.69 & 0.640 \\
\hline $\begin{array}{l}\text { Chao-Sørensen abundance-based } \\
\text { estimated similarity measures }\end{array}$ & 9.22 & 0.039 & 6.18 & 0.004 & 0.33 & 0.776 \\
\hline
\end{tabular}


Table 4. Summary results of Mantel tests showing $r$ and $P$ values of the matrix correlation between moth and vegetation assemblages and between moth assemblages and distance matrix.

\begin{tabular}{|c|c|c|c|c|c|}
\hline & & \multicolumn{2}{|c|}{ Distance } & \multicolumn{2}{|c|}{ Vegetation } \\
\hline & & $r$ & $P$ & $r$ & $P$ \\
\hline \multicolumn{6}{|l|}{ Primary forest } \\
\hline & Sørensen & 0.96 & 0.041 & 0.80 & 0.087 \\
\hline & Chao-Sørensen & 0.82 & 0.043 & 0.67 & 0.042 \\
\hline \multicolumn{6}{|c|}{ Secondary forest } \\
\hline & Sørensen & 0.06 & 0.631 & 0.07 & 0.668 \\
\hline & Chao-Sørensen & 0.18 & 0.452 & -0.50 & 0.872 \\
\hline
\end{tabular}




\section{Figure captions}

Figure 1. NMDS ordination based on Sørensen similarity measures of 'common' moth species, collected from primary (triangle) and post-logging forest (circle) in year 1 (closed symbols) and year 2 (open symbols).

Figure 2. Relationships between geographical distance and (a) Sørensen and (b) ChaoSørensen similarity values using moth assemblages collected from primary (closed triangle) and post-logging secondary (open circle) forest. Trend lines were drawn for primary (solid line) and secondary (dotted line) forests. 


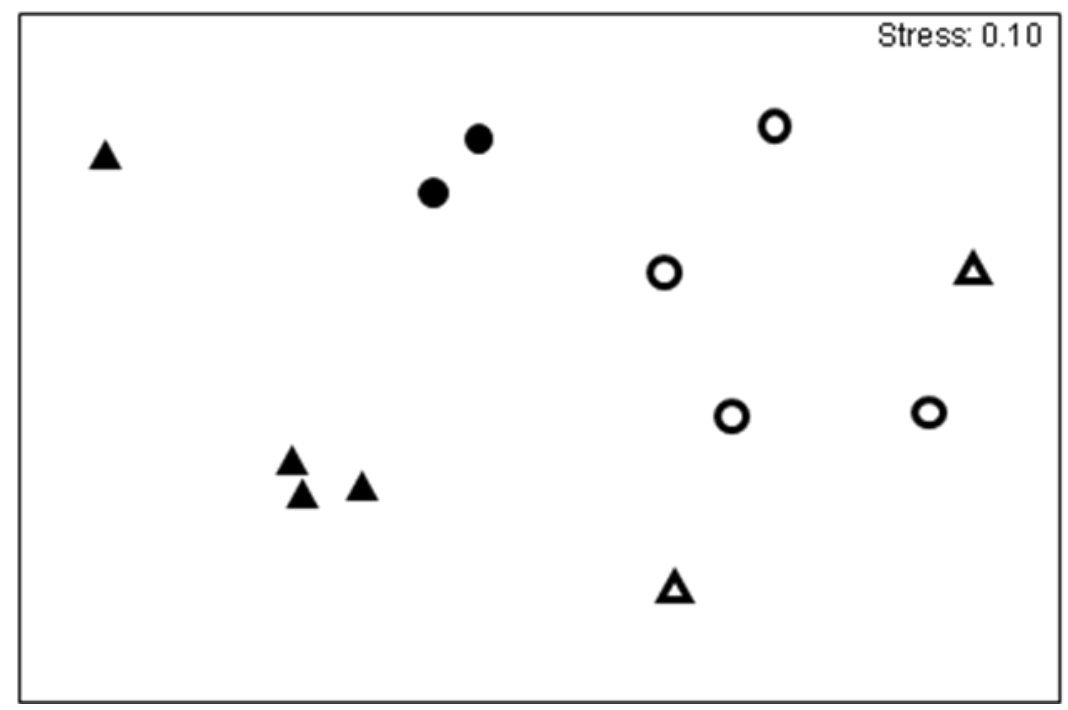

Figure 1 

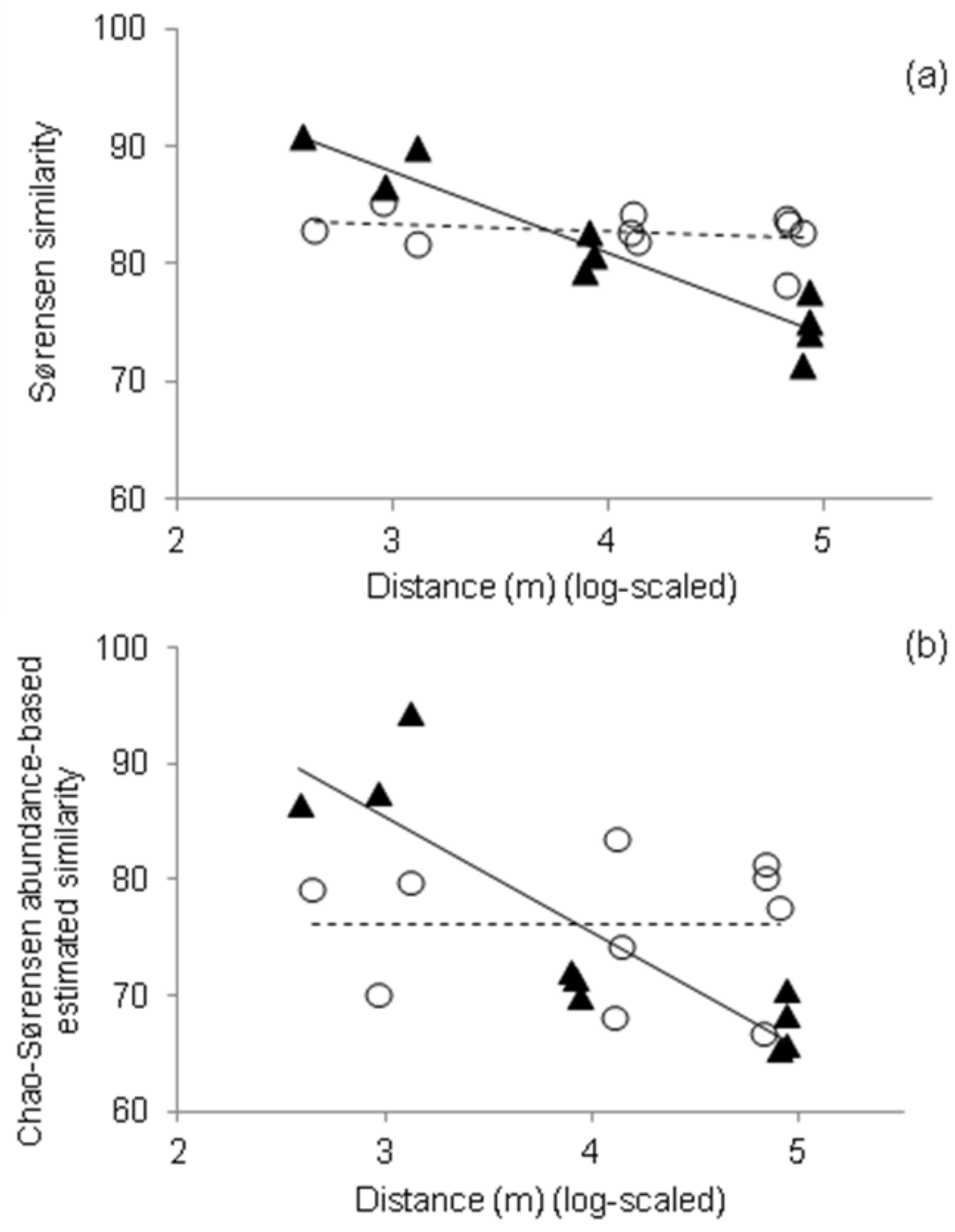

Figure 2 